\title{
METAFÍSICA DE LA SUBVERSIÓN: BADIOU, LAS VERDADES ETERNAS Y EL SUJETO
}

\section{METAPHYSICS OF SUBVERSION: BADIOU, THE ETERNAL TRUTHS AND THE SUBJECT}

\author{
Malfred Gerig ${ }^{1}$
}

Recibido 8 de noviembre 2020

Aceptado 26 de marzo 2020

\begin{abstract}
Resumen: El artículo se plantea indagar en la forma subjetiva capaz de producir una nueva secuencia de lo político desde la teoría del acontecimiento de Alain Badiou. Su tesis central es que la revolución post-cartesiana en la doctrina del sujeto tiene implicaciones directas en el concepto de lo político, por lo que el acontecimiento deviene en concepto clave de la teoría política. Para ello: 1. se confrontan las ontologías de Badiou y Heidegger. 2. Se reconstruye la ontología badiousiana teniendo como eje al concepto acontecimiento. 3. Se analiza la metafísica del sujeto badiousiana en tanto respuesta a las teorías modernas del sujeto y la verdad. 4. Se debaten las consecuencias de la filosofía de Badiou para el marxismo ortodoxo y el comunismo hermenéutico.
\end{abstract}

Palabras claves: Badiou; Acontecimiento; Sujeto; Metafísica; Política.

\begin{abstract}
The article proposes to investigate in a subjective way capable of producing a new sequence of the concept of the political from the theory of the Alain Badiou event. His central thesis is that the post-Cartesian revolution in the subject's doctrine has direct implications on the concept of the political, so the event becomes a key concept of political theory. To do this: 1 . the Badiou and Heidegger ontologies are confronted. 2. The Badiousian ontology is reconstructed with the concept of the event as its axis. 3. The metaphysics of the Badiousian subject is analyzed as a response to the modern theories of the subject and the truth. 4. The consequences of Badiou's philosophy for orthodox Marxism and hermeneutic communism are debated.
\end{abstract}

Keywords: Badiou; Event; Subject; Metaphysics; Politics.

1. Malfred Gerig (malfredgerig7@gmail.com) es sociólogo por la Universidad Central de Venezuela (UCV), Candidato a Magister en Ciencia Política por la Universidad Simón Bolívar (USB) e Investigador del Centro Nacional de Estudios Históricos (CNEH). Sus trabajos se centran en la economía política global y la teoría política emancipatoria. 


\section{Introducción}

La política, en tanto procedimiento de verdad por excelencia, aparece en el mundo anudada a una secuencia histórica y su sujeto. Para Badiou la última secuencia de la aparición de la política como práctica retirada del Estado y allende a la dominación se abre en 1917 con la Revolución de Octubre y se cierra en 1976 con la Revolución Cultural China. Así, a partir de la década de 1970 inicia un interludio en el que "el marxismo, el movimiento obrero, la democracia de masas, el leninismo, el partido del proletariado, el Estado socialista -todas las invenciones del siglo XX- ya no nos sirven" ${ }^{2}$. Por lo que en el campo de la teoría nos encontramos en un momento propicio para la reinvención de la hipótesis comunista bajo una nueva secuencia.

El objetivo de este trabajo es a partir del estudio de la teoría del acontecimiento de Badiou, la cual parte grosso modo de una propuesta ontológica de las multiplicidades en la que se despliega la categoría acontecimiento hasta una lógica del aparecer de las verdades eternas en un mundo, indagar en la forma subjetiva capaz de producir una nueva secuencia del concepto de lo político. Este objetivo se sujeta en la decisión político-filosófica según la cual el fundamento de la filosofía política es la doctrina del sujeto, ergo, una revolución en la doctrina del sujeto produce un desplazamiento en el recinto del concepto de lo político ${ }^{3}$. El argumento central del texto es que la revolución post-cartesiana en la doctrina del sujeto tiene implicaciones directas en la forma como pensamos lo político, por lo que el acontecimiento deviene en el concepto central de la teoría política contemporánea y representa un relanzamiento de la teoría de la revolución en la época del sujeto desustancializado y el materialismo democrático.

\section{Más allá de la presencia: Badiou como crítico de Heidegger}

La creación filosófica genuina, aquella capaz de interpretar un mundo o transformarlo, nace del diálogo. Cuatro nombres conforman el petit comité filosófico de Alain Badiou. Del lado de la admiración y la conti-

2. A. Badiou, "La hipótesis comunista", New Left Review, 49, (mar/abr 2008), p. 34.

3. Si la primera época de la doctrina del sujeto de la metafísica occidental se sustentó en el concepto de sujeto cartesiano, y la segunda época giró en torno a la problemática hegeliana del Absoluto monista que podemos caracterizar, no sin antes señalar la relación Hegel/Marx, como subjetividad, la tercera época de la doctrina del sujeto, que nace al mismo tiempo con Heidegger, Gramsci, Lacan y el psicoanálisis y la filosofía post-althusseriana, es la que origina la problematiza de la subjetivación, esto es, la respuesta del pensar a la época en la que el ser ya no puede ser concebido según el modelo de lo evidente o la representación desde el sujeto hacia el objeto

Thémata. Revista de Filosofía No61 (2020) pp.: 85-102. 
nuidad, no sin bifurcaciones, se encuentran Platón, Descartes y Hegel. Del lado de la enemistad, pero sobre todo de la oposición dialéctica creadora, encontramos a Heidegger. "La ontología filosófica contemporánea -dice Badiou- se encuentra enteramente dominada por el nombre de Heidegger"4. La apuesta filosófica de Badiou se inicia al hacerse cargo del giro ontológico propugnado por Heidegger con la intención de retarlo en su fundamento: la relación entre ser y verdad. Entonces, Badiou no estaría en desacuerdo con Heidegger en la máxima de "La tesis de Kant sobre el ser" según la cual "que el ser se haga digno de ser pensado no es ni un presupuesto arbitrario ni una invención gratuita" , sino en que al pensar el ser Heidegger erra el blanco del ser mismo. El asunto Heidegger-Badiou es la resurrección de la confrontación entre dos teorías del ser nacidas en la alborada griega del pensamiento occidental, a saber, la doctrina del pensar (noein) de cuño parmenidiano y la doctrina de la Idea de sello platónico. Si la tarea de Heidegger es producir un retorno hacia la relación entre ser, pensamiento y verdad invocando a Parménides en el momento histórico donde el nihilismo llegó a su cenit, la tarea de Badiou es refundar una metafísica del sujeto digna de una contemporaneidad que disfrazada de democracia euroccidental del fin de los tiempos oscila de Reagan y Thatcher a Trump.

Allí donde Heidegger posiciona una máxima de su hermenéutica de la historia de la filosofía al situar a Platón, Descartes y Hegel en la lista de sospechosos habituales de la metafísica en tanto que olvido del ser, Badiou va a intentar rehabilitarlos. En la interpretación badiousiana, la ontología occidental está trazada por una escisión entre el poema y el matema:

Hay dos vías, dos orientaciones, que guían el destino del pensamiento de Occidente. Una de ellas, apoyada en la naturaleza en el sentido griego originario, acoge en la poesía el aparecer como presencia ad-viniente del ser. La otra, apoyada en la Idea en el sentido platónico, somete la falta, la sustracción de toda presencia, al matema y separa así el ser del aparecer, la esencia de la existencia ${ }^{6}$

$\mathrm{Al}$ colocar a su proyecto filosófico en la acera de la sustracción y el matema, a la vez que posiciona a Heidegger del lado del poema y la presencia, Badiou rehabilita para la contemporaneidad una querella que escinde o asimila a cualquier postura teórica que se produzca bajo la matriz ontológica del pensamiento occidental. Para Badiou la clave se encuentra en la relación que la ontología concibe para ser y aparecer. Lo que Heidegger denuncia como un olvido que depara en olvido del propio olvido, para Ba-

4. A. Badiou, El ser y el acontecimiento, Buenos Aires, Manantial, 2003, p. 17.

5. M. Heidegger, "La tesis de Kant sobre el ser", Hitos, Madrid, Alianza, 2000, p. 362.

6. A. Badiou, El ser y el acontecimiento, cit., p. 145.

Thémata. Revista de Filosofía No61 (2020) pp.: 85-102. 
diou será consecuencia de la decisión, o lo que es lo mismo, de la subversión metafísica ${ }^{7}$.

Antes de ir al grano de la postura de Badiou acudamos a Heidegger. En Introducción a la metafísica se señala que "el estar en sí mismo para los griegos no significa otra cosa que el estar-aquí, el estar-a-la-luz. Ser significa aparecer (...) El ser es esencialmente en tanto que aparece" Allí Heidegger incurre en lo que Badiou denomina metafísica de la presencia ${ }^{9}$ acusando a Platón de ser el artífice de la escisión "entre el ente sólo aparente aquí abajo y el ser real en algún lugar de allá arriba" ${ }^{10}$. Al contrario, rehabilitando a la doctrina de la Idea platónica Badiou elige la vía ontológica en la cual la Idea produce una cesura radical entre el ser y el aparecer en la que "el ser pued[a] ser dicho a partir del momento en que una decisión del pensamiento lo sustrae a toda instancia de la presencia"11.

En consecuencia, un intento de refundar el pensamiento del ser debe tener cautela de abandonar apresuradamente a la metafísica, sin que ello sea óbice para realizar una crítica descarnada de sus versiones modernas. La ontología de Badiou, a diferencia de la de Heidegger, es sustractiva par excellence en tanto decide por la existencia y el aparecer en lugar de la presencia y la esencia. Así, el pensamiento es un procedimiento tanto de cesura, interrupción y deslinde como de sustracción por intermedio de la decisión. En este punto se hace evidente que en el proyecto badiousiano la preocupación ontológica no es el retorno a un inicio prontamente olvidado, sino el echar las bases para dar respuesta al vínculo entre verdad y sujeto ${ }^{12}$. Cuestión que vendría a ser el núcleo de la metafísica.

Es oportuno recordar que para Heidegger "la esencia de la libertad, vista desde la esencia de la verdad, se revela como un exponerse en el desocultamiento de lo ente"13. Desde la posición de Badiou, la postura de Heidegger significa un irracionalismo óntico en el que se pierde la cesura que introduce el sujeto. Lo que no está dispuesto a aceptar Badiou es la respuesta que Heidegger da a la cuestión de la esencia de la verdad en tanto ello implica la desaparición del sujeto y la metafísica. Sin embargo,

7. Ibid., p. 144.

8. M. Heidegger, Introducción a la Metafísica, Barcelona, Gedisa, 2001, p. 97.

9. Véase A. Badiou, El ser y el acontecimiento, cit., p. 17-18-19.

10. M. Heidegger, Introducción a la Metafísica, cit., p. 101.

11. A. Badiou, El ser y el acontecimiento, cit., p.146.

12. Así anuncia Badiou el objetivo central de su proyecto filosófico: "Pretendo (...) que [verdad y sujeto] sean aquí reactivados desde una perspectiva diferente y que este libro funde una doctrina efectivamente poscartesiana, e incluso poslacaniana, de lo que para el pensamiento des-liga, a la vez, la conexión heideggeriana del ser y la verdad, e instituye al sujeto, no como soporte u origen, sino como fragmento del proceso de una verdad" Ibid., p. 24.

13. M. Heidegger, "De la esencia de la verdad”, Hitos, Madrid, Alianza, 2000, p. 160.

Thémata. Revista de Filosofía No61 (2020) pp.: 85-102. 
sin lugar a dudas es Heidegger quien abre el camino filosófico por donde transitará Badiou al señalar que

La «verdad» no es una característica de una proposición conforme enunciada por un «sujeto» humano acerca de un «objeto» y que luego «valga» no se sabe en qué ámbito, sino que la verdad es ese desencubrimiento de lo ente mediante el cual se presenta una apertura ${ }^{14}$

Pese a que en la noción de "desencubrimiento" ya se encuentra implícita en la apuesta heideggeriana por entender al ser -a partir del retorno parmenidiano- como lo ente en su totalidad. También es insoslayable el hondo significado de la problematización del sujeto romo de la modernidad hecha por Heidegger a través de la cuestión del Dasein que su "metafísica de la presencia" le permite. Siendo esto lo que lo conduce a la inquietud por la producción de la apertura o emergencia, cuestión que no es más que el antecedente de la noción acontecimiento en tanto concepto central de la filosofía en la época de la ausencia de fundamento.

\section{El ser y el acontecimiento: la apuesta ontológica y lógica de Badiou}

La preocupación central de la filosofía de Badiou es el efecto del sujeto. Partamos estableciendo una hipótesis: la ontología de Badiou procuró interpretar, pero sobre todo resistir, al dictamen de su propio tiempo ${ }^{15}$. La apertura acontecimental representada por la Revolución Mundial de $1968^{16}$ condujo a Badiou a tomar un abordaje histórico a la hora de pensar al sujeto. En Teoría del sujeto, el libro representativo de la impronta causada en él por la Revolución Cultural Proletaria China y el Mayo de 1968, "las masas figuran como el término dinámico, inventivo y «en extinción» de la historia, una causalidad evanescente que llega a «consistir» en la medida en la que un partido marxista-leninista bien organizado es capaz de purificar y sostener la fuerza revolucionaria"17. Allí la dialéctica entre lo uno y lo múltiple, que en su consideración es el impasse original de la filosofía,

\section{Ibid., p. 161.}

15. "Badiou se opone clara y radicalmente al impulso antiplatónico posmoderno, cuyo dogma básico es que ha caducado definitivamente la época en que aún era posible basar un movimiento político en la referencia directa a alguna verdad eterna, metafísica o trascendental" S. Žižek, El espinoso sujeto. El centro ausente de la ontología política, Buenos Aires, Paidós, 2001, p. 142.

16. Véase I. Wallerstein, Geopolítica y geocultura. Ensayos sobre el moderno sistema mundial, Barcelona, Kairós, 2007, p. 94.

17. P. Hallward, "Alain Badiou: Orden y acontecimiento. Acerca de Logiques des mondes de Alain Badiou”, New Left Review, 53, (nov/dic 2008), p. 92.

Thémata. Revista de Filosofía Nº1 (2020) pp.: 85-102. 
se dirime con la aparición de las masas en tanto sujeto que encarna la posibilidad de cualidad y fuerza ${ }^{18}$. Con la victoria de la contrarrevolución monetarista a finales de 1970 y la clausura representada por el segundo intervalo de la hipótesis comunista ${ }^{19}$, la cuestión pasa ser la posibilidad misma de la filosofía, su pertinencia para el cambio de la vida. De Teoría del sujeto a El ser y el acontecimiento se produce un desplazamiento que va del despliegue interpretativo al que nos arroja el acontecimiento hacia la resistencia que se interroga por las condiciones de existencia/aparición del sujeto capaz de relanzar una metafísica otra, esto es, post-cartesiana. Resistir es producir las condiciones de emergencia de una metafísica para el cambio de la vida.

Así, El ser y el acontecimiento de 1988 apuesta por el giro ontológico para propugnar en favor de la vigencia de la filosofía ${ }^{20}$. Refundar la ontología para no claudicar en la vigencia de las verdades eternas. La decisión de Badiou es volver a la cuestión de lo uno y lo múltiple para con la ayuda de esa nueva categoría que es el acontecimiento despejar las posibilidades de aparición de una doctrina del sujeto efectivamente post-cartesiana. La pregunta de Aristóteles, ¿qué es el ser en tanto que ser? vertebra inicialmente, mas no consuma, la meditación. Al enfrentarse a esta interrogante Badiou declara: "estamos en el punto de una decisión, la de romper con los misterios de lo uno y de lo múltiple en los que la filosofía nace y desaparece, Fénix de su consumación sofistica" ${ }^{21}$. La tesis que impugna las condiciones de la ontología occidental se expresa: "lo uno no es". Con ella se clausura la identidad entre el ser y lo uno, pero sobre manera, el entendimiento del ser como presencia, siendo sustituida por la subversión metafísica que entiende al ser como aparición. Por eso "lo uno, que no es, existe solamente como operación (...) No hay uno, sólo hay cuenta-por-uno. Lo uno, al ser una operación, es jamás una presentación” ${ }^{22}$. Así queda establecido el a priori ontológico que lleva a Badiou hacia la teoría de conjuntos: el ser es múltiple en tanto que presentación en la que no ha ocurrido la operación de cuenta-por-uno, la cual, a su vez, estructura una situación o convierte a la multiplicidad en presentación. La lección para la interrogante sobre qué es el ser en tanto que ser es radical: "no hay sino

18. A, Badiou, Teoría del sujeto, Buenos Aires, Prometeo Libros, 2008, p. 26.

19. A. Badiou, "La hipótesis comunista", cit., p. 34.

20. El diagnostico de Badiou va en contrasentido al sentido común de la filosofía de su tiempo. Para él, no nos encontramos ante un ocaso, sino ante la necesidad de un paso hacia adelante que procure volver sobre la cuestión del ser, la verdad y el sujeto. Véase A. Badiou, Manifiesto por la filosofía, Buenos Aires, Nueva Visión, 1989.

21. A. Badiou, El ser y el acontecimiento, cit., p. 33.

22. Ibid., p. 34.

Thémata. Revista de Filosofía No61 (2020) pp.: 85-102. 
situaciones. La ontología, si existe, es una situación”"23. Se hace evidente la bifurcación entre la ontología de la presencia de cuño parmenidiano que resuena en Heidegger y el gesto platónico de Badiou que reivindica la importancia de la presentación, la sustracción y la formalización.

En seguida, Badiou debe pasar por el escabroso pasaje de la dialéctica entre el Ser y la Nada al que toda filosofía se ha remitido, incluyendo a Hegel, Heidegger y su maestro Sartre ${ }^{24}$. Tejiendo un hilo desde Platón a Cantor, Badiou logra una teorización convincente al tiempo que digna del espíritu de la época ya que asimila y responde sin claudicar a las preocupaciones centrales de la posmodernidad. Si lo uno no es, lo múltiple es. Pero es de dos formas, como múltiple consistente e inconsistente: la consistencia se relaciona con la presencia inercial mientras que la inconsistencia con la operación de cuenta-por-uno o estructuración. Si para Hegel la dialéctica entre el Ser y la Nada cuando no sucumbe a la representación coloca la atención en el devenir, para Badiou el quid del asunto radica en la presentación que escinde a la multiplicidad consistente e inconsistente. Ahora bien ¿puede ser pensado lo múltiple inconsistente? ¿Acaso no es desde Parménides hasta Heidegger el intento más genuino de la filosofía? Para Badiou es el gran error en el que han incurrido las metafísicas de la presencia: "la multiplicidad inconsistente es como tal, impensable. Todo pensamiento supone una situación de lo pensable, es decir, una estructura, una cuenta-por-uno" ${ }^{25}$. Al concebir al ser como universo pre-simbólico, el ser y el pensar dejan de ser una y la misma cosa. Badiou introduce a la Nada como identidad del ser, la cual antes del procedimiento sustractivo es puro vacío. Así, la diada ser y nada es sustituida por la dupla dialéctica (es decir: no binaria) Ser y Acontecimiento, nombres del vacío y la cesura. Con este movimiento se reactiva a la Idea platónica ahora asimilada como lo que comunica el sueño inasible del ser y su presentación en un mundo.

La noción de Vacío-Nada que realiza Badiou, en búsqueda de la anhelada revolución post-cartesiana, intenta dar respuesta tanto a lo múltiple puro como a una situación presentada. El concepto de situación-que en Lógicas de los Mundos será remplazado por el concepto de mundoplantea la paradójica cuestión de que en un mundo dado lo uno siempre es. "No hay nada que pueda ser presentado-dice Badiou- sin ser contado"26. Si una situación está siempre estructurada, ¿qué ha de ser de la escisión entre lo múltiple consistente e inconsistente? La respuesta de Badiou es

23. Ibid., p. 36.

24. Para la relación de Badiou y Sartre véase F. Jameson, "Badiou y la tradición francesa", New Left Review, 102 (nov-dic-2016).

25. Ibid., p. 46.

26. Ibid., p. 67.

Thémata. Revista de Filosofía No61 (2020) pp.: 85-102. 
que en el marco de una situación lo múltiple inconsistente sea nada ${ }^{27}$. La operación sustractiva de contar-por-uno relega a toda presencia impresentable a un ser en la nada. Vacío es el nombre a la sutura en el ser de la situación, o la cara oscura de la operación de cuenta-por-uno: "el vacío es el nombre del ser -de la inconsistencia- según una situación"28. Hasta aquí, en apariencia, Badiou desestima la potencia disruptiva del vacío. Antes al contrario, el acontecimiento será la categoría que reivindique la potencia del vacío. Mediante un recurso muy cercano a Hegel, Badiou argumenta que "la ontología está (...) obligada a proponer una teoría del vacío" 29. Siguiendo este argumento, se puede afirmar que para que el pensamiento del ser no sea ni un presupuesto arbitrario ni una invención gratuita debe ir acompañado de un pensamiento del acontecimiento. La ontología es siempre ontología social.

¿Qué es el acontecimiento? La consumación de la meditación sobre el ser-en-tanto-ser se da con la pregunta por "lo que no es el ser-en-tanto-ser". Para dilucidar este asunto Badiou debe contraponerse de nuevo con Heidegger, esta vez, en lo referente a la decisiva cuestión de lo que su ontología concibe por "naturaleza" y su co-extensiva "Nada". A diferencia de la ontología de Heidegger, en la que -según la interpretación que se aduce en $E l$ ser y el acontecimiento- el ser es concebido como el desocultarse de una presencia plena que se esconde en la naturaleza y se muestra en la obra de arte para fundar lo otro de la naturaleza en el propio terreno de la naturaleza ${ }^{30}$, con Badiou lo distinto al ser es también otro de la naturaleza pero no nace en ella sino que es su opuesto radical en tanto que inestable y a-normal. A ese otro de lo natural Badiou la bautizará como lo histórico. Vale señalar que este procedimiento rescribe las oposiciones clásicas de la filosofía e inscribe a la categoría acontecimiento como central para dar cuenta de la singularidad que se presenta sin estar contenida en la "normalidad" de la situación.

$\mathrm{El}$ gesto de Badiou es pensar la dialéctica entre normalidad y singularidad con el trasfondo ontológico de las multiplicidades a la luz de la lección sustractiva, es decir, que no todo lo que se presenta está representado. "Es racional pensar lo a-normal, lo anti-natural -por consiguiente, la historia- como omnipresencia de la singularidad..." ${ }^{31}$. En este punto el argumento parece ir al fondo de un problema central de la filosofía: la existencia de una brecha insuperable entre el mundo y su representación, o, en lenguaje de nuestro autor, cuando dada una situación existe un múltiple

27. Ibid., p. 69.

28. Ibid., p. 71.

29. Ibid., p. 72.

30. Ibid., p. 195.

31. Ibid., pp. 196-197.

Thémata. Revista de Filosofía No61 (2020) pp.: 85-102. 
presentado mas no representado. Entre la presentación y la falta de representación se abre paso la singularidad. ¿Qué ocurre si ninguno de los elementos está presentado dada una situación? Allí se encuentra la genuina preocupación de Badiou, donde el vacío se expresa en la situación a través de un múltiple totalmente singular por no estar presentado más que como múltiple sin términos. "Llamaré sitio de acontecimiento a un múltiple (...) totalmente a-normal, es decir, tal que ninguno de sus elementos está presentado en la situación" ${ }^{32}$. En el orden del ser el sitio de acontecimiento dibuja un efecto evanescente de estructura capaz de sustraerse a la cuenta-por-uno a partir de la emergencia de lo que estrictamente es Nada.

En este punto brota la pregunta por el fundamento: ¿podemos situar a Badiou directamente en el terreno del pos-fundacionalismo? ¿Acaso la distinción entre naturaleza e historia no abona el terreno para, por un lado, un fundamento del ser y, por el otro, un pos-fundacionalismo histórico? La respuesta de Badiou es unívoca: "los sitios fundan la situación, puesto que en ella son términos absolutamente primeros, que interrumpen la situación según la procedencia combinatoria" ${ }^{33}$. Aquí (parece) entrar en juego la proclividad badiousiana por privilegiar a lo que irrumpe en la estructura del ser en detrimento de la estabilidad del ser mismo. En la medida en que un múltiple sea absolutamente singular, esto es, que no esté presentado en ninguno de sus términos, no puede reducirse a una operación de cuenta pretérita. Para decirlo en otras palabras: la aparición del acontecimiento como aquello que interrumpe en el orden del ser funda gracias a que su vacío "absoluto" impide que el orden del ser sea capaz de replicarse a sí mismo mediante combinaciones con su propio es.

La apuesta ontológica de Badiou no es por el acontecimiento en detrimento del ser, sino por el acontecimiento como concepto que hace advenir, aparecer en su potencia, al ser. La pobreza de nuestro tiempo reside en identificar a naturaleza e historia otorgando a esta última las cualidades de la primera: normalidad, estabilidad, naturalidad. El argumento por excelencia de Badiou al respecto es que "la naturaleza es absoluta, la historicidad es relativa"; sin embargo, frente a la concepción de la historia con un sentido unívoco propia del marxismo del siglo XX sentenciará que "la historia es naturalizable, pero la naturaleza no es historizable" ${ }^{34}$. Así las cosas, el sitio de acontecimiento es singular a un punto de la situación y no, como lo pensó el marxismo ortodoxo, adherible a la totalidad. Badiou recoge del espíritu de su tiempo que la sucesión de normalidad que identificamos con lo natural es tan consustancial a la existencia como el

32. Ibid., p. 197.

33. Ibid., p. 198.

34. Ibid., p. 198.

Thémata. Revista de Filosofía №61 (2020) pp.: 85-102. 
acontecimiento. Aunque también nos recuerda que la historia es "en la precariedad representativa de los sitios de acontecimientos que se va a revelar, el azar de un suplemento, que el ser múltiple inconsiste"35. Estamos, pues, ante un pensamiento pos-fundacional.

\section{Hacia una nueva metafísica del sujeto}

La indagación filosófica badiousiana no está orientada a producir una nueva configuración de la comprensión del ser, sino en ocasionar una revolución en la teoría del sujeto que encadene, de forma distinta a la cartesiana, la relación entre verdad y sujeto. La apuesta badiousiana se lee así:

\footnotetext{
Está siendo desarrollada una doctrina post-cartesiana del sujeto cuyo origen puede atribuirse a prácticas no filosóficas (la política o la relación instituida con las «enfermedades mentales») y su régimen de interpretación, marcado por los nombres de Marx (y de Lenin), de Freud (y de Lacan), está intrincado en operaciones, clínicas o militantes, que exceden el discurso transmisible 36
}

Pese a que de manera sorpresiva Badiou no incluye a Heidegger en la pléyade de precursores de la teoría post-cartesiana del sujeto, coincide con él en que la época se caracteriza por la imposibilidad del sujeto para fundar o soportar a la verdad. "El sujeto contemporáneo es vacío, escindido, a-sustancial, irreflexivo" 37 . ¿Puede ser la verdad lo que configure al sujeto en la época del estar irreflexivo? De ser así, ¿qué tipo de verdad y fundada en qué? Basta con decir que la categoría central en este punto para Badiou, y en la que evoca la inspiración platónica, es lo genérico, esto es, las fuentes de la verdad. Así como el acontecimiento es lo otro del ser y la historia lo otro de la naturaleza, la verdad es lo otro del saber. El saber no tiene relación con el acontecimiento, ni con los procesos subjetivos que ocasiona. Su hacer es la clasificación y el discernimiento de los determinantes que operan en una situación, optando siempre por unas propiedades en detrimento de otras de acuerdo a criterios enciclopédicos ${ }^{38}$. La verdad, al contrario, se consustancia con lo indiscernible, de ahí su relación con el acontecimiento y la intervención de cesura: "una verdad reagrupa todos los términos de la situación que están conectados positivamente con el nombre del acontecimiento"39. En la acera de enfrente del saber, las verdades reagrupan a todos los elementos implicados en la apertura que origina el acontecimiento, al tiempo que conectan a una

35. Ibid., p 200.

36. Ibid., p. 9.

37. Ibid., p. 11.

38. Cf. Ibid., p. 364.

39. Ibid., p. 372.

Thémata. Revista de Filosofía No61 (2020) pp.: 85-102. 
situación con su infinito genérico. Siendo sólo "el amor, el arte, la ciencia y la política" los procedimientos genéricos que "generan al infinito verdades sobre las situaciones, verdades sustraídas del saber y contadas por el estado sólo en el anonimato de su ser" 40 .

El sujeto tiene la tarea de ser un operador de conexión fiel capaz de discernir en medio del acontecimiento una verdad genérica. Como queda dicho en Lógicas de los mundos, de lo que se trata es de fundar una nueva metafísica del sujeto ${ }^{41}$. Para entender las dimensiones de este paso vale con comparar el concepto de sujeto que nos ofrece Badiou con las clásicas concepciones de la metafísica moderna:

Un sujeto no es una sustancia (...) Un sujeto no es tampoco un punto vacío (...) Un sujeto no constituye para nada la organización de un sentido de la experiencia (...) Un sujeto no es invariante de la presentación (...) Un sujeto es calificado (...) Un sujeto no es un resultado, como tampoco es un origen ${ }^{42}$

Claramente Badiou dirige la artillería contra las limitaciones de la doctrina del sujeto-sustancia de origen hegeliano que el marxismo ortodoxo vulgarizó como teleología de la revolución proletaria. El quid de la crítica es la cuestión del sentido. Mientras que en la filosofía de la historia de muchos marxismos la verdad instaura el sentido, Badiou escinde verdad y sentido otorgándole al sujeto la posibilidad de instituir una verdad más que de clausurar el mundo tras esa instauración. El sujeto post-cartesiano es la "configuración local de un procedimiento genérico que sostiene una verdad"

Un grupo de conceptos acompañan a esta doctrina del sujeto y permiten indagar hasta qué punto sus efectos son post-cartesianos. En primer lugar, la subjetivación es lo que relaciona a la cesura generada por la intervención acontecimental con su propia verdad, convirtiendo a la intervención en expresión de la verdad más allá de la situación. Segundo, ¿qué relaciona los términos de una situación con el acontecimiento? La tarea de indagar en la relación entre el azar y el acontecimiento sin requisitos externos le corresponde al sujeto. Como la verdad, la materia del acontecimiento solo le rinde cuentas al acontecimiento mismo no al saber de la enciclopedia como externo y retrospectivo. En tercer lugar, más que como conciencia, el sujeto en tanto operador de sitio se relaciona con la verdad en el acontecimiento como una confianza, es decir, desarrolla la verdad del acontecimiento bajo las coordenadas indiscernibles del propio acontecimiento. La confianza produce una nominación, esto es, el nombre del

40. Ibid., p. 378.

41. A. Badiou, Lógicas de los mundos. El ser y el acontecimiento, 2, Buenos Aires, Manantial, 2008 , p. 51.

42. A. Badiou, El ser y el acontecimiento, cit., pp. 431-432.

43. Ibid., p. 431.

Thémata. Revista de Filosofía No61 (2020) pp.: 85-102. 
universo por-venir ${ }^{44}$. En cuarto lugar, la cuestión del forzamiento presenta el problema de cómo el saber se relaciona con el acontecimiento y afronta lo indiscernible propio de este. El trabajo del sujeto es ejecutar el proceso de forzamiento, o, en otras palabras, "un sujeto es un saber que pende de la verdad, de la que es su momento finito" 45 . Por último, en la que es la implicación anti-cartesiana de mayor envergadura, el sujeto no funda la verdad como en el modelo apofántico o las filosofías de la conciencia sino que se encuentra capturado por esta. "Lo que [el sujeto] produce es la verdad misma (...) pero la infinitud de esa verdad lo trasciende" 46 .

En lugar de protegerse ante el azar de la decisión, calificar las similitudes y unificar a lo singular como en el modelo cartesiano, para la doctrina badiousiana, un sujeto "fuerza la decisión, descalifica lo desigual y salva lo singular" ${ }^{47}$. Queda abierta la vía para las destinaciones del sujeto post-acontecimental en la que se encadenen de forma otra verdad y sujeto.

\section{Subjetivación: la toma de postura ante el acontecimiento}

Una vez hemos indagado en las bases del dispositivo ontológico que Badiou despliega para la formulación de una doctrina del sujeto capaz de ejercer de sino entre el acontecimiento y las verdades eternas, ha llegado el momento de prestar especial atención a la política. En una postura a la que adherimos, según Badiou la modernidad política nace con la Revolución Francesa en tanto que es a partir de allí que se produce una separación fidedigna entre Estado y política ${ }^{48}$. En consecuencia, la política puede ser conservadora cuando es subsumida por el Estado o puede ser emancipatoria cuando es capaz de subsumir a la máquina estatal. Para decirlo en el lenguaje de Hegel, entre Estado y política hay un juego de ser para sí o ser para otro cuyo derrotero determina el carácter conservador o revolucionario de la política: de predominar el Estado triunfa la conservación, de prevalecer la política triunfa la emancipación. Esto es lo que podemos denominar el camino sustractivo. De ahí que, así como la historia del capitalismo es también la historia de las luchas anticapitalistas, la historia de la hipótesis comunista es siempre la historia de los interludios donde el Estado subsumió a la política, id est, la normalización de la dominación. Cuando Badiou sostiene que "el movimiento (siglo XIX) y el partido

44. Ibid., p. 440.

45. Ibid., p. 446.

46. Ibid., p. 447.

47. Ibid., p. 450.

48. Cf. I. Wallerstein, El moderno sistema mundial, Vol. IV: El triunfo del liberalismo centrista, 17891914, México, Siglo XXI, 2014.

Thémata. Revista de Filosofía No61 (2020) pp.: 85-102. 
(siglo XX) fueron modos específicos de la hipótesis comunista; [y] ya no es posible volver a ellos" ${ }^{49}$ más que posmarxista está tratando de revitalizar la hipótesis a partir de la constatación de que el cuerpo de verdad ${ }^{50}$ que le sirvió durante dos siglos ha quedado obsoleto. El movimiento badiousiano es volver a la dialéctica "entre el sujeto (como estructura) y la subjetivación (como acto)" "51 para dilucidar la aparición de un cuerpo ya no fundado en la subjetividad del sujeto sino configurado desde su subjetivación, esto es, la toma de postura ante el acontecimiento.

La centralidad que acoge el concepto de cuerpo en Lógicas de los mundos es clave para comprender la apuesta por el aparecer en la filosofía de Badiou al tiempo que su pertinencia a la hora de desentrañar las posibles tomas de postura ante el acontecimiento. Una vez producido el acontecimiento, el cuerpo es lo que permite al sujeto operacionalizar la ruptura, es decir, el cuerpo subjetivable es un vehículo de subjetivación. Se hace evidente que sin cuerpos subjetivables el acto de subjetivación es endeble (haciendo alusión a las verdades políticas) a la normalización de la dominación. Lo que está en juego aquí es la relación entre el mundo que abre el acontecimiento (presente) y la organización lógica del mundo que empieza a quedar atrás (pasado). Este dilema es resuelto por Badiou a través de una muy sofisticada ontología política de la decisión y la relación, la cual, evocando al concepto de acto, pasa a denominarse toma de postura. En sus palabras:

La posición tomada respecto de la existencia de ese cuerpo es lo real, la materialidad, de la posición tomada respecto del acontecimiento. Pero un acontecimiento es la perturbación del orden del mundo (...) testificada por el relevo de un existente. ${ }^{52}$

A diferencia de la doctrina cartesiana en la que el sujeto funda al mundo, en la doctrina badiousiana el sujeto configura el mundo en tanto es el operador cuya toma de postura relaciona, como clausura o apertura, los órdenes trascendentales de ese mundo. En lugar de sujeto fundante, a este nuevo sujeto debemos comprenderlo como un fragmento que adviene con el acontecimiento y a través de un cuerpo subjetivable decide la relación entre dos mundos. La performatividad del sujeto, sin embargo, no es determinada por su relación con el mundo que configura sino por como su

49. A. Badiou, "La hipótesis comunista", cit., pp. 34-35.

50. "Un cuerpo de verdad es el resultado de incorporación a las consecuencias del acontecimiento de todo lo que, en el mundo, ha experimentado máximamente su potencia" A. Badiou, Segundo manifiesto por la filosofía, Buenos Aires, Manantial, 2010, p. 97.

51. A. Badiou, Lógicas de los mundos. El ser y el acontecimiento, 2, cit., p. 69.

52. Ibid., p. 99.

Thémata. Revista de Filosofía No61 (2020) pp.: 85-102. 
toma de postura ante el acontecimiento abre la posibilidad de introducir en un mundo a las verdades eternas: política, ciencia, arte y amor.

Las figuras del sujeto son la actualización innovativa con que Badiou intenta resolver el problema de Platón según el cual: "cómo nuestra experiencia de un mundo particular (...) puede abrirnos un acceso a verdades eternas, universales" ${ }^{33}$. La tipología de tomas de postura ante el acontecimiento elaborada por Badiou comprende: 1. el sujeto fiel, 2. el sujeto reactivo, 3. el sujeto oscuro, 4. la resurrección. Acudamos a la política para aclarar a cada una de las figuras. Siendo natural de lo político la dialéctica entre Estado y política el sujeto fiel es quien funda el presente con su toma de postura ante el acontecimiento, que no es otra que "entusiasmo por la novedad, fidelidad activa a lo que llegó para conmocionar localmente las leyes del mundo"54. El sujeto fiel es quien construye el presente a partir del cual las demás figuras del sujeto se posicionan del lado de la reacción al acontecimiento. El sujeto reactivo, por su parte, es aquel que niega el acontecimiento como novedad y milita por un presente perenne. Su actitud es inerte al acontecimiento, es decir, que si este no hubiese pasado todo continuaría igual, así "anula la novedad en la potencia tranquila de la conservación" ${ }^{55}$. Un tercer tipo de figura la encarna el sujeto oscuro cuyo procedimiento es la forclusión del significante acontecimental. En política la subjetividad oscura queda fehacientemente retratada en todas aquellas posturas para las cuales lo nuevo siempre hace identidad con la catástrofe y por tanto los intentos de emancipación conducen a mayor dominación. Por último, se encuentra la resurrección, esto es, el plus de la subjetividad fiel donde se trae de nuevo a escena una verdad eterna que creíamos olvidada. Como sostiene Badiou: "todo sujeto fiel puede reincorporar al presente acontecimental el fragmento de verdad cuyo antiguo presente había pasado debajo de la barra de ocultación"56.

$\mathrm{Si}$-como ha aclarado Heidegger ${ }^{57}$ - la filosofía occidental desde Aristóteles hasta Leibniz giró en torno a la cuestión de la causa y su inextricable relación con la metafísica, con las teorizaciones de Heidegger y Badiou aparece un pensamiento ocupado por las consecuencias. Este giro queda retratado cuando Badiou sostiene que "lo real de un sujeto reside en las consecuencias (consecuencias en un mundo) de la relación, que constituye a ese sujeto, entre una huella y un cuerpo"58. ¿Qué consecuencias acarrea para la filosofía este desplazamiento telúrico?

53. A. Badiou, Segundo manifiesto por la filosofía, cit., p. 114.

54. Ibid., p. 100.

55. Ibid.

56. A. Badiou, Lógicas de los mundos. El ser y el acontecimiento, 2, cit., p. 85.

57. M. Heidegger, "De la esencia del fundamento", Hitos, Madrid, Alianza, 2000.

58. A. Badiou, Lógicas de los mundos. El ser y el acontecimiento, 2, cit., p. 101.

Thémata. Revista de Filosofía No61 (2020) pp.: 85-102. 


\section{Consideraciones finales: Badiou y el acontecimiento ante el marxismo y la hermenéutica}

\section{1 ¿Hacia un marxismo de la subjetivación?}

Partamos de nueva cuenta con otra hipótesis: una revolución/configuración en la doctrina del sujeto produce un desplazamiento del recinto del concepto de lo político. A partir de allí se hace pertinente la pregunta: ¿qué ha de ser del concepto de lo político en la época del sujeto desustancializado? Tratemos de otorgar luz a esta interrogante desde la relación entre la nueva doctrina del sujeto a la que nos convoca Badiou con la anterior secuencia entre doctrina del sujeto y recinto del concepto de lo político, a saber, la marxista-hegeliana vulgar.

Para referirse al acontecimiento, novum de su filosofía con respecto a la historia de la filosofía, Badiou señala que "lo importante aquí es destacar que un acontecimiento no es la realización de una posibilidad inherente a la situación misma o dependiente de las leyes trascendentales del mundo. Un acontecimiento es la creación de nuevas posibilidades" ${ }^{59}$. Si recordamos que para la teoría de la revolución marxista-leninista la objetividad de la situación era el índice de verdad de la revolución, podemos interpretar a la teoría del acontecimiento de Badiou como una superación de la teoría de la revolución que dominó la secuencia marxista-hegeliana del concepto de lo político en sus significantes básicos: objeto, sujeto, posibilidad, imposibilidad, sentido. Dicho en otras palabras: un relanzamiento de la teoría de la revolución en la época del sujeto desustancializado y el materialismo democrático bajo el nombre de teoría del acontecimiento.

El idilio distante y a-subjetivo del marxismo ortodoxo ${ }^{60}$ por la realización de las condiciones objetivas implicaba una postura de clausura tanto ante la posibilidad en lo imposible que abre todo acontecimiento como ante la decisión que nomina al acontecimiento del aparecer al ser. El marxismo ortodoxo fue incapaz de descifrar la dialéctica entre proceso histórico-económico, es decir, la dinámica de la economía política de la sociedad capitalista, y la revolución social, esto es, la lucha de clases. La muestra flagrante de esa incapacidad fue la construcción del sentido de la Historia como un subterfugio de la revolución. Así, la verdad de la política emancipatoria mas que encarnada en su sujeto, el proletariado, era externalizada o en su objeto el capital al aducir que la condición objetiva de toda revolución es el desarrollo de las fuerzas productivas, o, por otra parte,

59. A. Badiou, "La idea del comunismo", en A. Hounie (comp.), Sobre la idea del comunismo, Buenos Aires, Paidós, 2010, p. 23.

60. Véase F. Jameson, Valencias de la dialéctica, Buenos Aires, Eterna Cadencia, 2013, cap. 15.

Thémata. Revista de Filosofía No61 (2020) pp.: 85-102. 
hacia la Historia como "agente" de un sentido que aguardaba a largo plazo la victoria del proletariado instando en el corto plazo a la pasividad de la subjetivación política. Este impasse parece estar en núcleo de la filosofía marxiana localizable desde el prólogo a la Contribución a la crítica de la economía política del propio Marx ${ }^{61}$, demostrable por el atolladero en la dialéctica entre estructura y superestructura, pero, sobre todo, en la confusión para dilucidar quién es el sujeto de la historia: si el proletariado en su constante lucha de clases contra la clase capitalista o el sistema histórico capitalista en su auge, expansión y declive.

El intento de Badiou por superar estos límites del marxismo ortodoxo pasa por recuperar lo "in-fundado de la prescripción política" ${ }^{2}$. Esta reinscripción empieza a ser legible a partir de una aclaratoria:

Ni Marx ni Lenin dijeron que la lucha de clases fuera por sí misma identificable con la práctica política. La lucha de clases es una categoría de la Historia y el Estado, y no es sino bajo condiciones completamente singulares como constituye una materia de la política ${ }^{63}$

En el punto donde, como nos insiste Mallarmé "todo pensamiento emite una tirada de dados"64, Badiou sentenciará que "las verdades no tienen ningún sentido" ${ }^{65}$. En lugar de estar preso en el trascendental de la sociedad capitalista, el acontecimiento político abre la posibilidad de insertar un nuevo trascendental en un mundo. En consecuencia, la política emancipatoria debe rechazar la construcción de un subterfugio mediante la identidad entre Historia y sentido, abogando, en cambio, por la fidelidad a lo imposible vuelto posible en el despliegue del acontecimiento.

\subsection{Verdad e interpretación: el sujeto fiel como intérprete.}

¿Cómo puede basarse la política emancipatoria en las verdades eternas cuando el concepto de "verdad" ha sido uno de los más señalados y atacados como propios de la dominación? Dos hermeneutas partidarios de la interpretación como Vattimo y Zabala nos dicen: "para distanciarnos de la neutralidad "pacífica» de la metafísica, tenemos que abandonar, descartar o cancelar la verdad: el final de la verdad es el comienzo de la democracia" 66 . En un sentido diametralmente opuesto Badiou aduce que "... de

61. K. Marx, Contribución a la crítica de la economía política, México, Siglo XXI, 1980, p. 3.

62. A. Badiou, Condiciones, Buenos Aires, Siglo XXI, 2012, p. 216.

63. Ibid., p. 220.

64. S. Mallarmé citado en A. Badiou, El ser y el acontecimiento, cit., p 222.

65. A. Badiou, Condiciones, cit., p. 225.

66. G. Vattimo y S. Zabala, Comunismo hermenéutico. De Heidegger a Marx, Barcelona, Herder, 2012, p. 38.

Thémata. Revista de Filosofía No61 (2020) pp.: 85-102. 
donde la humanidad proviene es del alumbramiento de lo colectivo como verdad de lo mismo de lo que trata la política. Por eso excluye toda interpretación (...) como dice Caeiro: «Ser una cosa es no ser susceptible de interpretación»"67. Esta distancia entre dos teorizaciones del acontecimiento la podemos retrotraer al apasionado desapego de Heidegger para con la dialéctica en la década de 1920 expresada en Ontología. Hermenéutica de la facticidad donde la hermenéutica se concibe como un "modo unitario de abordar, plantear, acceder a ella, cuestionar y explicar la facticidad"68. En Lógicas de los mundos, al contrario, se reclama para las verdades eternas la misma pretensión que Heidegger reclama para la hermenéutica al señalar que "No hay más que cuerpos y lenguajes, sino que hay verdades" 69. La pregunta que adviene es si efectivamente no hay espacio para la interpretación en la doctrina de las verdades eternas de Badiou.

La apuesta que aquí se hace es que pese a las posturas teóricas encontradas entre el comunismo hermenéutico de Vattimo y Zabala y la dialéctica materialista de Badiou hay un canal de comunicación que se origina en los conceptos de intérprete en Vattimo y Zabala y sujeto fiel en Badiou. Según Vattimo y Zabala la principal conclusión que podemos obtener de la inversión nietzscheana de la verdad apofántica expresada en la máxima "no hay hechos, sólo interpretaciones, y esto también es una interpretación" es que "sólo hay hechos si nosotros los comprendemos como acontecimientos o sucesos en cuya creación contribuimos, como intérpretes, de una manera determinada"70. ¿Acaso no son los sujetos fieles badiousianos intérpretes en este sentido? ¿Acaso no es la subjetivación una toma de postura, esto es, una interpretación? Cualquier teoría del acontecimiento pone sus reservas sobre la tradición lenguajera del concepto de interpretación y Badiou no es la excepción, por eso señala que "la Idea no es un cuerpo en el sentido de lo dado inmediato (...) ni tampoco un lenguaje ni un nombre" ${ }^{71}$. Igualmente, una teoría de la interpretación que quisiera ser fiel al giro acontecimental no puede quedarse sujeta al lenguaje y debe dirigirse hacia una concepción de la interpretación más cercana a la existencia, es decir, al aparecer del acontecimiento en un mundo/estructura que nos convoca a la voluntad de poder. Colocar a lo político en el recinto donde aparece la verdadera vida, o en clave gramsciana, alojar a la sociedad política en la sociedad civil.

67. A. Badiou, Condiciones, cit., p. 237.

68. M. Heidegger, Ontología. Hermenéutica de la facticidad, Madrid, Alianza, 2008, p. 27.

69. A. Badiou, Lógicas de los mundos. El ser y el acontecimiento, 2, cit., p. 20.

70. G. Vattimo y S. Zabala, Comunismo hermenéutico. De Heidegger a Marx, cit., p. 137.

71. A. Badiou, Lógicas de los mundos. El ser y el acontecimiento, 2, cit., p. 26.

Thémata. Revista de Filosofía No61 (2020) pp.: 85-102. 
Lo característico de la época (1789-1992) en la que el sujeto revolucionario configuró al concepto de lo político fue, paradójicamente, tanto la proliferación de lo político a través de lo social, como la inhibición de la subjetivación acontecimental de la subjetividad mediante la creación de una identidad entre Historia y sentido. En la secuencia post-cartesiana de la doctrina del sujeto la subjetivación política se vive, en cambio, como interés, interpretación y decisión. Ello no quiere decir la superación de las verdades eternas sino el retorno de la nunca acabada lucha entre la política como emancipación alojada en lo social y la política como dominación alojada en el Estado.

\section{Bibliografía}

Badiou, A.: Manifiesto por la filosofía, Buenos Aires, Nueva Visión, 1989. Badiou, A.: El ser y el acontecimiento, Buenos Aires, Manantial, 2003.

Badiou, A.: "La hipótesis comunista", New Left Review, 49, (mar/abr 2008). Badiou, A.: Lógicas de los mundos. El ser y el acontecimiento, 2, Buenos Aires, Manantial, 2008.

Badiou, A.: Teoría del sujeto, Buenos Aires, Prometeo Libros, 2008.

Badiou, A.: Segundo manifiesto por la filosofía, Buenos Aires, Manantial, 2010.

Badiou, A.: "La Idea del comunismo", en A. Hounie (comp.), Sobre la idea del comunismo, Buenos Aires, Paidós, 2010.

Badiou, A.: Condiciones, Buenos Aires, Siglo XXI, 2012.

Hallward, P.: "Alain Badiou: Orden y acontecimiento. Acerca de Logiques des mondes de Alain Badiou”, New Left Review, 53, (nov/dic 2008).

Heidegger, M.: Hitos, Madrid, Alianza, 2000.

Heidegger, M.: Introducción a la Metafísica, Barcelona, Gedisa, 2001.

Heidegger, M.: Ontología. Hermenéutica de la facticidad, Madrid, Alianza, 2008.

Jameson, F.: Valencias de la dialéctica, Buenos Aires, Eterna Cadencia, 2013.

Jameson, F.: "Badiou y la tradición francesa", New Left Review, 102 (novdic-2016).

Marx, K.: Contribución a la crítica de la economía política, México, Siglo XXI, 1980.

Vattimo G. y Zabala, S.: Comunismo hermenéutico. De Heidegger a Marx, Barcelona, Herder, 2012.

Wallerstein, I.: Geopolítica y geocultura. Ensayos sobre el moderno sistema mundial, Barcelona, Kairós, 2007.

Wallerstein, I.: El moderno sistema mundial, Vol. IV: El triunfo del liberalismo centrista, 1789-1914, México, Siglo XX, 2014.

Žižek, S.: El espinoso sujeto. El centro ausente de la ontología política, Buenos Aires, Paidós, 2001. 